\title{
A PROFILE OF CHILDREN WITH CEREBRAL PALSY: IDENTIFYING UNMET NEEDS IN HEALTH AND SOCIAL CARE
}

\author{
Fernando, $\mathrm{S}^{1}$, Wannakukoralage, $\mathrm{M}^{2}$, Athukorala, $\mathrm{T}^{3}$, Liyanaarachchi, $\mathrm{N}^{4}$ and \\ Wijesinghe, $\mathrm{C}^{5}$ \\ 1,2,3,5 Department of Community Medicine, Faculty of Medicine, University of Ruhuna, Sri Lanka \\ ${ }^{4}$ Department of Paediatrics, Faculty of Medicine, University of Ruhuna, Sri Lanka
}

\begin{abstract}
Provision of care to a child with Cerebral Palsy (CP) requires individualized assessment and management of all associated problems. They need special education and their families need social support to face day-to-day demands of caregiving. We reviewed the characteristics of 375 children with CP attending Teaching Hospital, Karapitiya to identify their health problems and current level of health and social care utilization. Data were collected through questionnaire-based interviews with caregivers or extracted from child's medical records. The results revealed that approximately $2 / 3^{\text {rd }}$ of the children had spastic quadriplegic CP and 54\% had some co-morbidity. The majority (30.9\%) had 3-4 functional problems. Problems with mobility (77.6\%), social activities of daily living (69.3\%), bladder/bowel function (70.4\%) and speech (57.9\%) were the common functional problems. Learning difficulties were reported in $29.3 \%$. Nearly $17 \%$ had behavioural and emotional problems. Approximately $98 \%$ of the children received physiotherapy. Despite higher numbers having problems with speech and activities of daily living, only $48 \%$ received speech therapy and less than $10 \%$ received occupational therapy. Among pre-school and school age children, over $70 \%$ had never attended school. Only $17.2 \%$ of school attendees received special education. Although nearly $70 \%$ was from rural, low socio-economic backgrounds, only $12.8 \%$ received any form of external financial support. We conclude that children with $\mathrm{CP}$ and their families have many unmet needs in the areas of therapy, special education and social support. These needs should be addressed adequately in developing long-term care plans for children with $\mathrm{CP}$, in order to achieve better outcomes.
\end{abstract}

Keywords: Cerebral palsy, unmet needs, health, special education, social support

\section{INTRODUCTION}

Cerebral palsy is a permanent disorder of movement and posture and the commonest cause of physical disability in children in many countries (Kriggler 2006, Werner 2006, Rosenbaum 2009). It is caused by non-progressive disturbances to one or more specific areas of the brain, usually occurring during fetal development; before, during, or shortly after birth; or during infancy.

The incidence of cerebral palsy among term infants is about 1.8 per 1000 live births (Rosen and Dickinson 1992). Increased survival of extremely preterm infants has lead to a change in the clinical picture of the disease. However, the global incidence of cerebral

Corresponding Author Email: cjw@med.ruh.ac.lk palsy has remained constant over the years, around 2.5 per 1000 live births (Missiuna et al, 2001, Kriggler 2006) and the incidence is supposed to be higher in developing countries (WHO 2005).

Cerebral palsy is characterized by an inability to fully control motor function, particularly voluntary control of muscles and coordination (Shanker and Mundkar, 2006, Kriggler 2006). Depending on which areas of the brain are affected, the affected children may show muscle tightness or spasticity, involuntary movement, disturbance in gait or mobility, difficulty in swallowing and problems with speech. Also these children can have abnormal sensation and perception, impairment of sight, hearing or speech, seizures, 
and/or mental retardation. Other problems, such as difficulties in feeding, poor bladder and bowel control, problems with breathing due to postural difficulties, pressure sores, and learning disabilities may arise in some occasions.

Management of cerebral palsy aims at helping the child achieve maximum potential in growth and development. This should be started as early as possible with identification of the very young child who may have a developmental brain disorder. A multidisciplinary team consisting of paediatricians, physiotherapists, occupational therapists, speech therapists, educators, nurses, social workers, and other professionals can assists the child as well as the family. As these children grow up, they may require support services such as educational and vocational training, independent living services, counseling, transportation, recreation/leisure programmes, and employment opportunities, all essential to the developing into adulthood.

However, not all children with cerebral palsy have equal access to these health and social services. Utilization of health services by children with special health care needs could be far less than ideal, especially in resource poor settings (van Dyke et al, 2004, Szilagyi et al, 2004, Parish et al, 2012). Although children with special needs should receive special focus in health and social care and policy planning, data pertaining to such children and their care needs are scarce in Sri Lanka, both at the national and regional levels. Significant gaps exist in evidence relating to the status and services for people with disabilities, barriers to education and access to healthcare (Peiris-John et al, 2013).

While the functional capability of a child with cerebral palsy depends on his/her developmental stage, the actual performance of the child will relate to contextual factors like the role of parents, family and availability of resources (e.g. rehabilitation equipment). These children and their caregivers must therefore be empowered to face the mounting challenges of inclusive living to guarantee equal opportunities for them. Identifying the unmet needs in the areas of health, education and social care for these children is essential for planning and organizing the much needed services. This in turn will enhance the health and quality of life of the children themselves as well as their families. This study aimed to review the characteristics of children with cerebral palsy attending a tertiary care hospital, with a view to evaluate current level of health and social care received by them.

\section{MATERIALS AND METHODS}

This study was conducted using secondary data from a database of 375 children with cerebral palsy and their caregivers attending Teaching Hospital, Karapitiya (THK), Galle, Sri Lanka. THK is the only tertiary care institution in the whole of the Southern province which possesses a network of facilities necessary for multi-disciplinary management of children with cerebral palsy.

The database was created for a study on caregiver burden in cerebral palsy. Study participants were children aged between 1 to 12 years with a confirmed diagnosis of cerebral palsy and their principal caregivers, who were permanent residents of Galle district. The children receiving services from paediatric wards, outpatient paediatric clinics, Rheumatology and Rehabilitation Unit (RRU) and Speech and Language Therapy Unit (SLTU) of the THK were included in the sample. The original database included information collected through questionnaire based interviews with the caregivers or extracted from the child's medical records. Relevant socio-demographic, disease related and services related data were extracted and analyzed in this study. The initial data collection and data extraction were done by trained pre-intern medical officers. Ethical approval for the study was obtained from the Ethical Review Committee of the Faculty of Medicine, University of Ruhuna, Sri Lanka.

The socio-demographic variables included the age and gender of the child; age, ethnicity, residential area, educational status, employment status, income and social class of the caregiver. Social class was categorized according to the classification given by Barker and Hall (1991) based on father's occupation (or mother's occupation if father is unemployed or had a lesser occupational status than the mother). The professionals, semi-professional and non-manual workers were classified as upper social classes, where as skilled and unskilled manual workers or unemployed were considered as lower social classes.

The functional status of the child was assessed by a Consultant Paediatrician based on the information available in the medical records of the child. The data 
analysis was done using SPSS (version 18.0) statistical software package.

\section{RESULTS}

The study included 375 caregiver child pairs. The mean age of the children in the sample was $3.2( \pm 2.7)$ years and there was a slight male preponderance (51.2\%).

Ninety seven percent of the principal caregivers were the mothers and nearly $2 \%$ were grandmothers.
Fathers contributed as principal caregivers in approximately $1 \%$ of the children. Age of the caregivers ranged from 18-65 years and the mean age was $32.4( \pm 7.2)$ years. Over $70 \%$ were from rural, low socio-economic backgrounds. Majority of the caregivers $(75 \%)$ were currently unemployed and $20 \%$ have given up their jobs to look after the child. The basic socio-demographic profile of the children and their caregivers is shown in Table 1.

Table 1: Characteristics of the sample of children with cerebral palsy and their caregivers $(N=375)$

\begin{tabular}{|c|c|c|}
\hline \multicolumn{2}{|l|}{ Characteristic } & \multirow{2}{*}{$\frac{\text { Number }(\%)}{303(80.8)}$} \\
\hline Age of the child & Less than 5 years & \\
\hline & $5-8$ years & $44(11.7)$ \\
\hline & Over 8 years & $28(7.5)$ \\
\hline \multirow[t]{2}{*}{ Sex } & Male & $192(51.2)$ \\
\hline & Female & $183(48.8)$ \\
\hline \multirow[t]{3}{*}{ Caregiver age } & Less than 30 years & $147(39.2)$ \\
\hline & $30-49$ years & $222(59.2)$ \\
\hline & 50 years or above & $6(1.6)$ \\
\hline \multirow[t]{2}{*}{ Residential area } & Urban & $104(27.7)$ \\
\hline & Rural or estate & $271(72.3)$ \\
\hline \multirow[t]{2}{*}{ Ethnicity } & Sinhala & 347 (92.6) \\
\hline & Other & $28(7.4)$ \\
\hline \multirow[t]{3}{*}{ Caregiver educational status } & Primary education or below & $62(16.5)$ \\
\hline & Post-primary education & $224(59.7)$ \\
\hline & Secondary education or above & $89(23.8)$ \\
\hline \multirow[t]{2}{*}{ Caregiver employment status } & Employed & $25(6.7)$ \\
\hline & Not employed & $350(93.3)$ \\
\hline \multirow[t]{2}{*}{ Monthly family income } & Rs. 10,000 or less & $263(70.1)$ \\
\hline & Above Rs. 10, 000 & $112(29.9)$ \\
\hline \multirow[t]{2}{*}{ Social class } & Upper social classes & $100(26.7)$ \\
\hline & Lower social classes & $275(73.3)$ \\
\hline
\end{tabular}

Approximately $2 / 3^{\text {rd }}$ of the children had spastic quadriplegic cerebral palsy and $54 \%$ had some comorbidity such as epilepsy or heart diseases. Majority of the children (30.9\%) had 3-4 functional problems.

The limitation of motor functions was the commonest functional problem $(77.6 \%)$ in this sample. Problems with bladder/bowel function (70.4\%) and impaired social activities of daily living $(69.3 \%)$ were also prevalent (Table 2). 
Table 2: Type of cerebral palsy and the functional problems among the children $(N=375)$

\begin{tabular}{lll}
\hline Variable & & Number (\%) \\
\hline Type of Cerebral palsy & Spastic Quadriplegic & $250(66.7)$ \\
\hline & Spastic Hemiplegic & $32(8.5)$ \\
\hline & Spastic Diplegic & $27(7.2)$ \\
\hline & Athetoid cerebral palsy & $2(0.5)$ \\
\hline Functional problems & Unclassified & $64(17.1)$ \\
\hline & Seizures & $191(50.9)$ \\
\hline & Visual problems & $98(26.1)$ \\
\hline & Hearing problems & $72(19.2)$ \\
\hline & Speech problems & $217(57.9)$ \\
\hline & Learning difficulties & $110(29.3)$ \\
\hline & Problems of emotion \& behaviour & $65(17.3)$ \\
\hline & Problems of mobility & $291(77.6)$ \\
\hline & Problems of social activities of daily living & $260(69.3)$ \\
\hline & Problems of bladder and bowel function & $264(70.4)$ \\
\hline
\end{tabular}

Table 3 shows the use of health, education and social care services by the children with cerebral palsy in this sample.

Utilization of health services: The vast majority of children in the sample used some form of therapy service. Approximately $98 \%$ of the children received physiotherapy. Despite the higher prevalence of speech problems (approximately 58\%), only $48 \%$ received speech therapy. Although over $70 \%$ had problems with mobility and activities of daily living, only fewer than $10 \%$ received occupational therapy.

Status of schooling: Among pre-school and school age children $(\mathrm{N}=164)$, over $70 \%$ had never attended school and only $29(17.7 \%)$ were receiving a formal education. None of the children attended a special school designed for children with special needs. Among those attending schools $(\mathrm{N}=29)$, only $17.2 \%$ received special education.
Availability of social support and special facilities: Regarding Social care and assistance, the majority of the children with cerebral palsy in this sample $(86.4 \%)$ did not have any special facilities at home. The only available special facilities included special equipments such as special seating and mobility aids.

\section{DISCUSSION}

In this study sample, many deficits in the use of specific therapy were observed, indicating the unmet needs in these areas. Similarly, the use of educational and social services was far from optimal, probably as a result of unavailability and difficulties in access. Lack of awareness and direction could be a contributory factor for poor utilization of available health care in some instances. While many were attending this tertiary care institution for physiotherapy, the speech and occupational therapy services in the same facility were not utilized by them (Table 3).

Table 3 Utilization of health and social care services by the children with cerebral palsy

\begin{tabular}{lll}
\hline Type of service & & Number $(\%)$ \\
\hline Therapy services $(\mathrm{N}=375)^{*}$ & Drug therapy & $200(53.3)$ \\
\hline & Physiotherapy & $367(97.9)$ \\
\hline & Speech therapy & $181(48.3)$ \\
\hline & Occupational therapy & $37(9.9)$ \\
\hline
\end{tabular}




\begin{tabular}{lll}
\hline Use of educational services (N=164) & Currently attending school & $29(17.7)$ \\
\hline & Currently not attending school & $19(11.6)$ \\
\hline & Never attended school & $116(70.7)$ \\
\hline Type of school (N=29) & Special school & $0(0.0)$ \\
\hline & General school/special class & $5(17.2)$ \\
\hline & General school/general class & $14(48.3)$ \\
\hline & Preschool & $10(34.5)$ \\
\hline Receipt of financial support (N=375) & None & $327(87.2)$ \\
\hline & From Government & $37(9.9)$ \\
\hline & From non-governmental organizations & $11(2.9)$
\end{tabular}

*Percentages do not add up to 100 due to multiple responses*

Children with special needs have a greater demand for health care than those without special needs (Szilagyi 2004, Newacheck and Kim, 2005), resulting in increased health care costs. From our results it was evident that over $70 \%$ of the children with cerebral palsy belonged to economically deprived families and a considerable proportion (20\%) of caregivers had given up their jobs to look after the child (Table 1). Moreover, the majority lived in rural areas, and the services of therapists are virtually limited to major hospitals in urban settings, compelling them to travel over long distances. The interplay of these conditions can create a vast economic burden. Van Dyke (2004) reported similar conditions among children with disabilities in the United States. Although unmet health care needs were observed in a minority compared to our study sample, the proportion with economic hardships was substantial, partly as a result of their caregivers cutting back or quitting work. Provision of financial assistance through government or non-governmental sources would be a crucial factor to ensure an acceptable level of health care for these children. The need of financial assistance for families of children with special health care needs has been highlighted by other studies also (Bertule and Vetra, 2014).

Children with disabilities are more likely to have low school enrolment and high dropout rates (UNICEF, 2012). Even with a high national primary school enrolment rate at $92 \%$, many children with disabilities in Sri Lanka have not started schooling according to the Ministry of Social Welfare (2003). Similarly, the Ministry is concerned that the attrition rates of children who have disability are high. Both these concerns are reflected in our findings where only a minority of children (less than 30\%) had ever attended school and a substantial dropout rate of $11.6 \%$ was observed (Table 3 ).

The majority of the children who were attending schools or preschools in this sample were enrolled in general classes of mainstream schools along with the other typically developing children (Table 3). Although this could be viewed as a positive step towards inclusive education, the extreme competitiveness and the tight work schedules prevailing in the classroom settings in Sri Lankan schools may place them at a disadvantage.

Provision of care for a child with a disability is a challenging experience for the caregivers (Raina et al, 2005, Brehaut et al, 2009). The role of social support is identified as an important factor in preventing negative consequences of caregiving (Ha et al, 2011). Apart from the minority (12.8\%) who received some financial assistance from the Department of Social Services and a few non-governmental organizations, the families of children with cerebral palsy in this sample have not received any other form of external social support (Table 3). Considering that over $70 \%$ of the sample is socio-economically deprived, our findings reflect an enormous gap between the needs and services. In addition, the financially stable families could also benefit from other forms of social support such as counseling and respite care. Such services are yet an unavailable luxury for the caregivers of the disabled in Sri Lanka.

This study is the first attempt at identifying the health and social care needs of an important group of children with disabilities in a low resource setting. Its 
major strength is the use of data from a larger sample. However, our findings are limited by the fact that the children and caregivers studied are those already accessing the health services. Therefore, the prevalence of health care utilization could be an overestimation of the actual usage observed in a community based survey. Since it is evident from the results that the receipt of care is not optimal even among the users, we can safely assume that the unmet needs are even greater among those whom we failed to capture in this study. Secondly, the sample was derived from those attending a government health care facility which offers free health services and normally caters to low and middle income categories. This can lead to an under-representation of economically stable families in the sample, which could partially explain the greater numbers of participants being among disadvantaged groups. A third limitation is the use of secondary data, limiting the comprehensiveness of the survey. For example, we were unable to assess the need for certain aspects of care such as dental services or nutritional care. Lack of recorded data on such aspects among the current assessment of children itself is a clear indication that these areas are not adequately addressed during the routine care provision and suggests the possibility of further unmet needs. Further research is needed to evaluate the specific health and social care needs in these children and the extent to which these needs are met by their care plans.

\section{CONCLUSIONS}

This study revealed that there are many unmet health and social care needs among children with cerebral palsy, especially in the areas of specific therapy (speech therapy/occupational therapy), education and social support. Early identification of disabilities and formulation of long term care plans involving multidisciplinary management is a priority in provision of care for these children, in order to achieve better outcomes.

\section{ACKNOWLEDGEMENTS}

The authors wish to thank the Director, all the consultants and staff attached to paediatric wards, clinics, Rheumatology \& Rehabilitation Unit and Speech \& Language Therapy Unit of the Teaching
Hospital, Karapitiya for granting permission and support during the study, Dr. Dr. W.H.K.N. Kumari, Dr. V. Lelwala and Dr. Y.L.V. Lakmali for their support with data collection and all the caregivers and the children who participated in the study for their kind co-operation.

\section{REFERENCES}

BARKER, D.J.P., HALL, A.J., 1991, Practical Epidemiology, 4th ed. (Edinburgh, UK: Churchill Livingstone)

BERTULE, D., VETRA, A., 2014, The family needs of parents of preschool children with cerebral palsy: The impact of child's gross motor and communications functions, Medicina 50, 323-328.

BREHAUT, J.C., KOHEN, D.E., GARNER, R.E., MILLER, A.R., LACH, L.M., KLASSEN, A.F., ROSENBAUM, P.L., 2009, Health Among Caregivers of Children With Health Problems: Findings From a Canadian Population-Based Study. American Journal of Public Health, 99 (7), 1254-62.

HA, J., GREENBERG, J.S., SELTZER, M.M., 2011, Parenting a Child With a Disability: The Role of Social Support for African American Parents, Families in Society: The Journal of Contemporary Social Services, 405-411.

KRIGGLER, K.W., 2006, Cerebral palsy: an overview. American Family Physician, 73 (1), 91-100.

MINISTRY OF SOCIAL WELFARE, 2003, National Policy on Disability for Sri Lanka, (Colombo, Sri Lanka: Ministry of Social Welfare)

MISSIUNA, C., SMITS, C., ROSENBAUM, P., WOODSIDE, J., LAW, M., 2001, The prevalence and incidence of childhood disabilities: Facts and issues, A paper published by the McMaster University, Ontario, Canada.

NEWACHECK, P.W., KIM, S.E., 2005, A National Profile of Health Care Utilization and Expenditures for Children With Special Health care needs, Archives of Paediatric and Adolescent Medicine, 159, 10-18.

PARISH, S., MAGANA, S., ROSE, R., TIMBERLAKE, M., SWAINE, J.G., 2012, Health care of Latino children with autism and other developmental disabilities: quality of provider interaction mediates utilization. American Journal of Intellectual \& Developmental Disability, 117(4), 304-15.

PEIRIS-JOHN, R.J., ATTANAYAKE, S., DASKON, L., WICKRAMASINGHE, A.R., AMERATUNGA, S., 2014, Disability studies in Sri Lanka: priorities for action, Disability and Rehabilitation, 36(20), 1742-8.

RAINA, P., O'DONNELL, M., ROSENBAUM, P., BREHAUT, J., WALTERS, S.D., RUSSELL, D., SWINTON, M., ZHU, B., WOOD, E., 2005, The health and well being of caregivers of children with Cerebral palsy. Paediatrics, 115 (6), 626-36.

ROSEN, M.G., DIKINSON, J.C., 1992, The incidence of cerebral palsy, American Journal of Obstetrics and Gynaecology, 167, 417- 423. 
ROSENBAUM, P., 2003, Cerebral palsy: what parents and doctors want to know. British Medical Journal, 326, 970974.

SANKAR, C., MUNDKAR, N., 2006, Cerebral palsy definition, classification, etiology and early diagnosis, Indian Journal of Paediatrics, 72, 865-8.

SZILAGYI, P.G., SHENKMAN, E., BRACH, C., LACLAIR, B., ZWIGONSKY, N., DICK, A., SHONE, L.P., SCHAFFER, V.A., COL, J.F., ECKERT, G., KLEIN, J.D., LEWIT, E.M., 2003, Children With Special Health Care Needs Enrolled in the State Children's Health Insurance Program (SCHIP): Patient Characteristics and Health Care Needs, Pediatrics, 112 (6 Pt 2), e508.

UNITED NATIONS CHILDREN'S FUND (UNICEF), 2012, The right of children with disabilities to education: A rights based approach to inclusive education, Geneva (Switzerland): UNICEF, p20.

VAN DYKE, P.C., KOGAN, M.D., MCPHERSON, M.G., WEISSMAN, G.R., NEWACHECK, P.W., 2004, Prevalence and Characteristics of Children with Special Health Care Needs, Archives of Paediatric and Adolescent Medicine,158(9), 884-890.

WERNER, D., 2006, Disabled village children. A guide for community health workers, rehabilitation workers and families, (Berkeley, CA: Hesperian Books)

WORLD HEALTH ORGANIZATION (WHO), 2005, Making every mother and child count: The World Health Report 2005, Geneva, WHO. 